\title{
Covid-19 Geçici Aşılama Kliniklerinin Atanmasına Sezgisel Bir Yaklaşım
}

\author{
Esra Çakır ${ }^{1}$, Mehmet Ali Taş ${ }^{2 *}$ \\ ${ }^{1}$ Galatasaray University, Faculty of Engineering and Technology, Department of Industrial Engineering, İstanbul, Turkey, (ORCID: 0000-0003-4134-7679), \\ ecakir@gsu.edu.tr \\ $2^{* *}$ Turkish-German University, Faculty of Engineering, Departmant of Industrial Engineering, İstanbul, Turkey, (ORCID: 0000-0003-3333-7972), \\ mehmetali.tas@tau.edu.tr
}

(2nd International Conference on Applied Engineering and Natural Sciences ICAENS 2022, March 10-13, 2022)

(DOI: 10.31590/ejosat.1082773)

ATIF/REFERENCE: Çakır, E., \& Taş, M. A. (2022). COVID-19 Geçici Aşılama Kliniklerinin Atanmasına Sezgisel Bir Yaklaşım. European Journal of Science and Technology, (34), 360-366.

Öz

Covid-19 virüsü nedeniyle Dünya Sağlık Örgütü tarafından 2020 yılında pandemi ilan edildi. Çeşitli ülkelerde, Covid-19 virüsüne karşı insan vücuduna bağışıklık kazandıran çok sayıda aşının üretimi çalışmaları halen devam etmektedir. Bu virüsle baş etmek için toplu aşılama çalışmaları yapılmaktadır. Toplu aşılama, aşıları ulaştırma ve süreç yönetimi açısından çok zor ve karmaşık bir iştir. Tüm hastaneler ve diğer sağlık merkezleri insanları aşılamak için kullanılsa da, sağlık merkezlerindeki Covid-19 hastalarını diğer hastalardan ayırmak ve aşıya daha hızlı erişim sağlanması için geçici aşı klinikleri de düşünülebilir. Bu çalışmada, İstanbul/ Türkiye'de yer alan bir ilçenin altı bölgesine hizmet verecek geçici aşı kliniklerinin aday yerlere atamaları incelenmiştir. Problemin doğrusal formülasyonu verilerek, Covid-19 aşılaması için çoklu tesis yerleşim problemi, revize edilmiş sezgisel tasarruf algoritması ile araştırılmıştır. Buna ek olarak, daha uygun maliyetli atama sonuçları incelenmiştir. Bölgenin tüm taleplerinin karşılanmak zorunda olunmadığı durumda toplam maliyeti gözlemlemek için Lagrange gevşetmesi kullanılmış ve ana modelle karşılaştırma yapılmıştır. Sonuçlar gelecekteki geçici merkezleri atama çalışmalarına rehberlik etmeyi amaçlamaktadır.

Anahtar Kelimeler: Covid-19, Sezgisel Tasarruf Algoritması, Lagrange Gevşetmesi, Çoklu Tesis Yerleşim Problemi, Geçici Aşılama Kliniği.

\section{A Heuristic Approach for Assignments of Covid-19 Temporary Vaccination Clinics}

\begin{abstract}
Due to the Covid-19 virus, a pandemic is declared by World Health Organization in 2020. In various countries, studies on the production of many vaccines that give immunity to the human body against the Covid-19 virus still continue. Mass vaccination has been carried out to deal with this virus. This process is a very difficult and complex task in terms of fast transportation and process management. Although all hospitals and other health centers are used to vaccinate people, temporary vaccination clinics can also be considered to separate Covid-19 patients in health centers from other patients and provide faster access to the vaccine. In this study, the location assignments of temporary vaccination clinics that will serve six regions of a district in Istanbul/Turkey are examined. The linear formulation of the problem is given, and the multi-facility location problem for Covid-19 vaccination is investigated with the revised saving heuristic algorithm. In addition, more cost-effective assignment results more examined and compared with the main model using Lagrange relaxation to observe the total cost of not assigning all demands of regions. The results are intended to guide future temporary center assignment studies.
\end{abstract}

Keywords: Covid 19, Saving Heuristic Algorithm, Lagrange Relaxation, Multi-Facility Location Problem, Temporary Vaccination Clinic.

*S Sorumlu Yazar: mehmetali.tas@tau.edu.tr 


\section{Giriş}

Aşılar, yaklaşık üç yüzyıldan daha fazla zamandır çeşitli hastalıkların önlenmesinde ve kontrolünde kritik rol oynamıştır (Plotkin, 2014). Aş1lama için genellikle hastaneler ve doktor muayenehaneleri gibi geleneksel sağlık merkezleri tercih edilse de, bu merkezlere ek olarak bir epidemi ya da pandemi sırasında eczaneler gibi alternatif yerler de aynı amaç için kullanılabilir (Bartsch vd., 2018). Söz konusu yerler çoğunlukla kolayca erişilebilir noktalarda yer aldıklarından geleneksel sağlık merkezlerine girmesi tehlikeli olan kişileri de aşılama imkanı sunar (Kim \& Mountain, 2017; Leibowitz vd., 2021).

Covid-19 virüsü nedeniyle milyonlarca insan hayatını kaybetti ve çok daha fazlası hastanelerde tedavi altına alındı (WHO, 2022). Salgının başlangıcının ardından tüm dünyada aşılama faaliyetlerine başlandı. 2021 yılının sonunda yaklaşık 4,5 milyar kişi en az bir doz aşı olmuştur (NY Times, 2022). Aşılama için alt yaş gruplarının da uygun görülmesi ve birden fazla doz gerekliliği nedeniyle aşılama faaliyetlerinin sürekli olarak devam etmesi gerekir (Ackerson vd., 2021). Ortaya çıkan bir salgınla toplu aşılama çalışmaları ile başa çıkmak mümkündür (Heymann \& Aylward, 2006). Bu kadar çok insanın aşılanması için sabit lokasyonlara ek olarak farklı aşı lokasyon alternatifleri düşünülebilir. Aşıların tüm insanlara uygun koşullarda uygulanabilmesi için aşı merkezine ihtiyaç olabilir (Gianfredi vd., 2021). Hastane ve eczane gibi geleneksel ve geleneksel olmayan yerlerde aşılama yapılabilse de, bu yerleşik merkezler tüm insanları aşılamak için yeterli görülmemektedir.

Aşılama faaliyetlerini artırmak ve kolaylaştırmak için kullanılan alternatiflerden biri de geçici aşılama klinikleridir. Geçici aşı klinikleri, kısa veya uzun süreler için herhangi bir yere kurulabilir. $\mathrm{Bu}$ alternatifin geçmişte çeşitli durumlar için kullanıldığı görülmüştür. Giles vd. (2018), geçici aşılama kliniklerinde yardıma muhtaç ve risk grubundaki kişiler için influenza aşısı uygulamasının sonuçlarını gözden geçirmiştir. Hannings vd. (2019), 27 geçici noktada kurulan ve eczane öğrencilerinin işlettiği influenza geçici aşılama kliniğinde aşılanan hastalardaki algıları incelemiştir. Chen vd. (2020), Amerika Birleşik Devletleri Houston'daki çocuklar için aşı sağlayan bir geçici klinik programını takip etmiştir. Böylece, geçici aşı kliniklerinin, Covid-19 aşılamasında da kullanılabileceği düşünülmektedir. Pandemide, geçici aş1 kliniklerinin belirli bir bölgede nereye yerleştirileceği konusunu hızlı bir şekilde belirlemek gerekir. Uygun bir atama programı ile insanlara daha az maliyetle ve daha etkin bir şekilde ulaşılabilir. Böylece kamu kaynakları daha doğru yönetilebilir. Bu atama problemi, çoklu tesis yerleşim problemi olarak kategorize edilebilir (Çakır vd., 2021; Çakır vd., 2022).

Atama problemleri, ulaştırma problemlerinin özel bir durumu olarak gösterilebilir. Literatürde, acil sağlık hizmetlerinin (Yang vd., 2004), ambulansların (Van Barneveld vd., 2016), hastane departmanlarının (Abdel-Basset vd., 2018) atama problemleri incelenmiştir. Bu özel problemler; Wimmert (Wimmert, 1958), dal-sınır (Ross \& Soland, 1975), Hungarian (Mills-Tettey vd., 2007) vb. algoritmalarla çözülebilir. Bunlara ek olarak, sezgisel algoritmalar da bu problemlerin çözümünde kullanılmaktadır.

Sezgisel algoritmalar, büyük ölçekli problemler için kısa sürede optimum sonuçlara yakın sonuçlar elde edilmesini sağlar. Literatürdeki birçok çalışmada aday yere atama problemleri için sezgisel yöntemler kullanılmaktadır. Srivastava'nın (1993) ortaya koyduğu sezgisel algoritma, tüm tesislerin başlangıçta açık olduğunu varsayar. Ardından kapatılacak tesisin belirlenmesi amaçlanır. $\mathrm{Bu}$ durum, açık tesisler için yaklaşık rotalama maliyetlerinin kullanılmasıyla mümkündür. Bir başka çalışmada, tasarruf algoritmasının bir versiyonu olan C-W algoritması Clark ve Wright (1964) tarafından kullanılmıştır. Araştırmada, tek depo araç rotalama problemlerine bir tasarruf konsepti sunulmuş ve optimum yapıya yakın bir araç rotalama yapısı bulmak için sezgisel bir greedy yöntem önerilmiştir. Kapasitesiz tesis yerleşim problemi için benzer bir greedy yaklaşım, Kuehn ve Hamburger'in (1963) çalışmasında yer almıştır. Çalışmada tüm tesislerin açık olduğu varsayılır ve ardından kapanışı kârda en büyük artışa yol açan tesisler teker teker kapatılmaktadır. Başka bir tasarruf sezgisel yöntemi ise Hansen vd. (1994) tarafindan uygulanmıştır. Önerilen yöntem, çoklu araç ve kapasiteye sahip tesislerin bulunduğu bir problemde kullanılmıştır. Yöntemin temel mantığı problemi üç alt probleme ayırmaya dayanır. Daha fazla maliyet iyileştirmesi mümkün olmadığında sezgisel algoritma durur.

$\mathrm{Bu}$ çalışma, önceki çalışmalara ek olarak, çoklu tesis yerleşim problemi için bir sezgisel tasarruf algoritmasını revize ederek literatüre katkıda bulunmaktadır. Metodoloji, bölgelerin tüm taleplerinin atanmak zorunda olmadığı durumda toplam maliyeti gözlemlemek için Lagrange gevşetmesi kullanılarak, kurulan modelin bir uzantısını da sunmaktadır. Önerilen algoritma, pandemi için geçici aşılama kliniklerinin atanmasında ilk kez uygulanmıştır.

Makalenin genel yapısı şu şekildedir: İkinci bölümde, çoklu tesis yerleşim problemi ve Lagrange gevşetmesi tanıtılmıştır. Daha sonra önerilen metodoloji sezgisel bir algoritma ile açıklanmıştır. Üçüncü bölümde, İstanbul'daki bir ilçenin altı bölgesi için önerilen metodolojinin uygulandığı bir geçici aşılama kliniği vaka analizi çalışması yer almaktadır. Ayrıca, Lagrange gevşetmesi kullanılarak, bölgedeki nüfusun tamamının aşılanması gerekmediği varsayımı altında, tüm talepleri geçici aşılama kliniklerine atanmak zorunda olmadığı durumu da incelenmiştir. Çalışmanın son bölümü olan dördüncü bölümde ise sonuçlar yer almaktadir.

\section{Materyal ve Metot}

$\mathrm{Bu}$ bölümde, uygulama konusu ve problemin yapısı ve önerilen sezgisel algoritma tanitılmaktadır.

\subsection{Problemin Yapısı}

Çoklu tesis yerleşim probleminin doğrusal programlama formülasyonu aşağıdaki gibidir:

\section{Girdiler:}

$c_{i j}=$ i'deki müşterinin talebini j'den karşılama (atama) maliyeti (mesafe veya seyahat süresine bağlı maliyet) $(i=1,2, \ldots, n)$ ve $(\mathrm{j}=1,2, \ldots, \mathrm{m})$

$d_{i}=$ i'deki müşterinin talebi ( kişi sayısı)

$f_{j}=\mathrm{j}$. aday yere tesis yerleşiminin maliyeti

$k=$ Yerleşim yapılacak tesis sayısı.

\section{Denklemler:}

$$
Z_{\text {min }}=\sum_{i=1}^{n} \sum_{j=1}^{m} c_{i j} d_{i} x_{i j}+\sum_{j=1}^{m} f_{j} y_{i}
$$

Şu koşullara göre:

$$
\sum_{j=1}^{m} x_{i j}=1 \quad(i=1,2, \ldots, n)
$$




$$
\begin{gathered}
\sum_{\mathrm{i}=1}^{\mathrm{n}} \mathrm{x}_{i j} \leq n y_{j} \quad(j=1,2, \ldots, m) \\
\sum_{j=1}^{m} y_{j}=k \\
x_{i j} \geq 0
\end{gathered}
$$

Amaç fonksiyonu (1), talep ağırlıklı atama ve tesislerin yerleştirilmesini içeren toplam maliyeti en aza indirir. Kısıt denklemi (2), her müşterinin talebinin tamamının atanması gerektiğini belirtir. Kısıt denklemi (3), j aday yerine atanan toplam müşteri talep oranının, atanan müşteri sayısını geçemeyeceğini tanımlar. Kısıt denklemi (4), yalnızca $\mathrm{k}$ adet aday yerin yerleşim için seçilmesi gerektiği anlamına gelir. Kısıt denklemi (5), i'deki müşterinin $\mathrm{j}$. aday yere atanan talep oranının pozitif bir reel sayı olduğunu ifade eder. Son olarak kısıt (6), eğer tesis j konumuna atanmışsa y değişkenin değerinin 1 , atanmamışsa 0 değeri alacağını göstermektedir.

Bir bölgedeki müşterilerin tüm taleplerinin karşılanmasının zorunlu olmadığ 1 durumda toplam maliyetini gözlemlemek için kısıt (2) gevşetilir. Dolayısıyla, gevşetilmiş çoklu tesis yerleşim probleminin doğrusal formülasyonu aşağıdaki gibi değişir:

\section{Girdiler:}

$c_{i j}=$ i'deki müşterinin talebini j'den karşılama (atama) maliyeti (mesafe veya seyahat süresine bağlı maliyet) $(i=1,2, \ldots, n)$ ve $(j=1,2, \ldots, m)$

$$
\begin{aligned}
& d_{i}=\mathrm{i} \text { 'deki müşterinin talebi (kişi sayısı) } \\
& f_{j}=\mathrm{j} . \text { aday yere tesis yerleşiminin maliyeti } \\
& k=\text { Yerleşim yapılacak tesis sayısı } \\
& u_{i}=\text { Lagrange çarpanı }
\end{aligned}
$$

Denklemler:

$$
Z(u)_{\min }=\sum_{i=1}^{n} \sum_{j=1}^{m}\left(c_{i j} d_{i}-u_{i}\right) x_{i j}+\sum_{j=1}^{m} f_{j} y_{i}+\sum_{i=1}^{n} u_{i}
$$

\section{Şu koşullara göre:}

Kisit denklemi (3-4-5-6).

\subsection{Sezgisel Algoritma}

Çoklu tesis yerleşim problemi için önerilen sezgisel algoritmada Kuehn ve Hamburger (1963) ile Clarke ve Wright (1964) tarafından yapılan çalışmalar temel alınmıştır. Önerilen yaklaşımımıza göre, ilk tesis minimum maliyetli bir aday yere yerleştirilir. Her tesisin yerleştirildiği yeni yer, çözümü daha da geliştirmelidir. Minimum maliyeti oluşturan düzende tesislerin sayısı ve yeri belirlenir. Sözü edilen sezgisel algoritmanın adımları aşağıdaki gibidir:

Adım 1: Müşteri ile aday yer arasındaki mesafe maliyeti (veya seyahat süresine bağlı maliyet) ve müşteri talebi bilgileriyle başlangıç matrisi oluşturulur.

Adım 2: Müşteri talebi ile mesafe maliyeti (veya seyahat süresine bağlı maliyet) çarpılarak taşıma maliyeti matrisi oluşturulur ve sütunların toplamları hesaplanır. (Hesaplamada tasarruflar pozitif, maliyetler negatiftir).
Adım 3: Bir tesis, minimum toplam maliyeti olan aday yere yerleştirilir (atanır). Bu yere, tüm müşsterilerin ataması yapılır.

Adım 4: Müşterilerin diğer aday yerlere atanması halinde, yer değiştirmelerinin tasarrufları hesaplanır.

Adım 5: Tasarrufların sütun toplamları hesaplanır ve bir sonraki tesis toplam maksimum tasarruflu sütuna atanır. Bu tasarruflara sahip müşteriler seçilen yere atanır.

Adım 6: Tasarruf matrisi gözden geçirilir. Tasarruf varsa Adım 5'e dönülür. Aksi takdirde, algoritma sonlandırılır.

Algoritma, minimum toplam maliyete ulaşıldığında biter. $\mathrm{Bu}$, aynı zamanda kurulacak yeni bir tesisin ek bir tasarruf sağlamadığı noktadır. Şekil 1, önerilen algoritmanın akış şemasını göstermektedir.

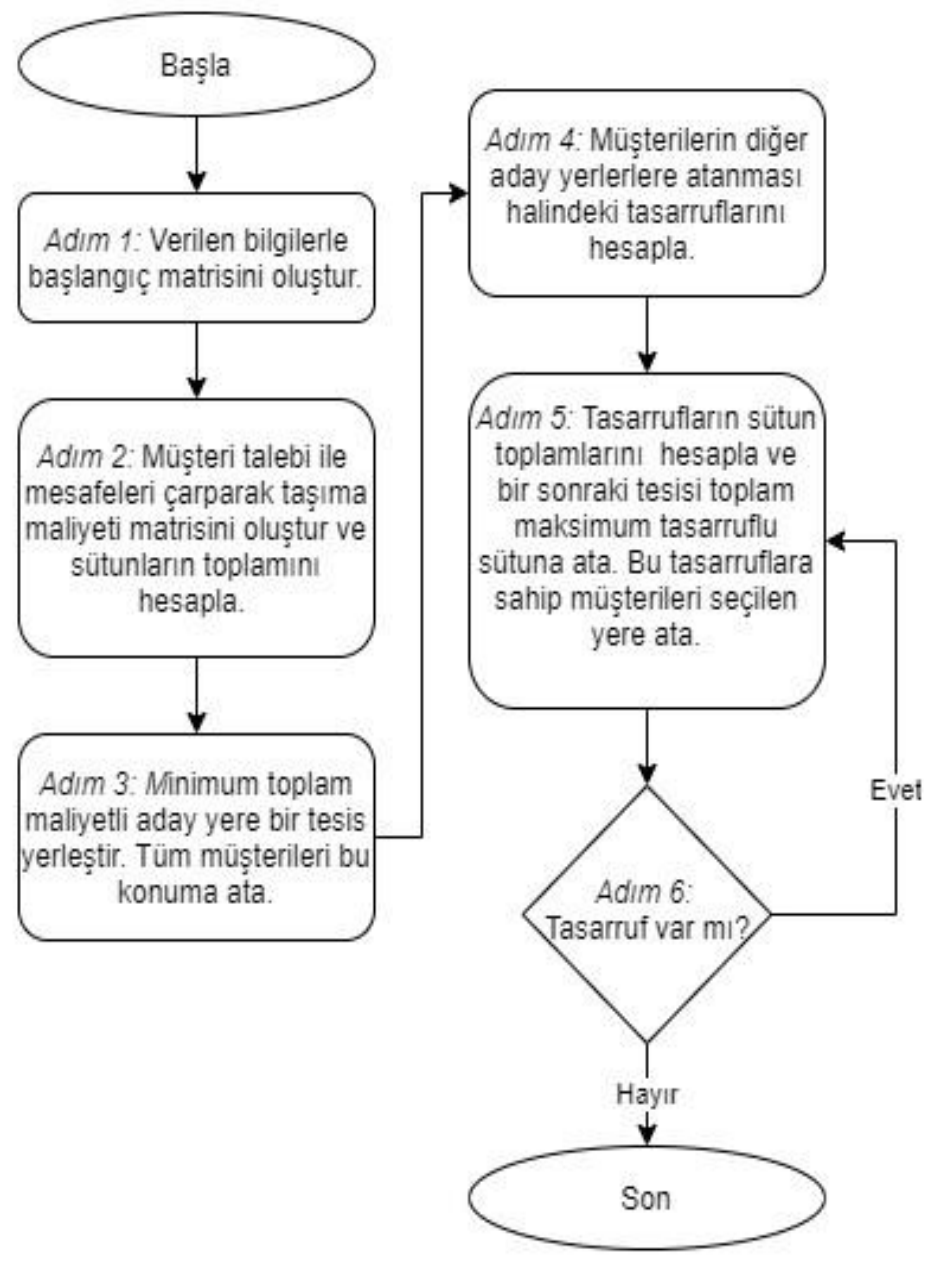

Şekil 1. Önerilen Algoritmanın Akış Şeması

\section{Vaka Analizi}

Covid-19 virüsüne karşı aşılama çalışmaları için ilk etapta Türkiye'deki geleneksel sabit sağlık merkezlerinin kullanılmasına karar verilmiştir. Bu çalışmada, aşılamayı hızlandırmak ve Covid19 temaslı ve hastalarını diğer hastalardan ayrı tutmak için geçici aşılama klinikleri önerilmiştir. Ayrıca geçici aşılama kliniklerinin sağlık merkezlerindeki yoğunluğu azaltarak daha dengeli bir kapasite kullanımına hizmet edeceği düşünülmektedir. 
Vaka analizi olarak, uzmanlar tarafından İstanbul'un seçilen bir ilçesi hizmet alacak altı bölgeye ayrılmıştır. Hizmet verecek geçici aşı klinikleri için beş aday yer belirlenmiştir. Hangi aday yerlere klinik yerleştirileceği ve açılan kliniklerin hangi bölgelere hizmet vereceği araştırılmak istenmiştir.

Söz konusu uygulama için önerilen metodolojinin adımları aşağıdaki gibi uygulanmıştır.

Adım 1: İlk matris, müşteri bölgesi ile aday yerleşim yeri arasındaki uzaklık maliyeti (£) ve bölgede yaşayan insanların nüfusu (talebi) ile ilgili bilgilerle oluşturulur (Tablo 1).

Tablo 1. Başlangıç Matrisi

\begin{tabular}{|c|c|c|c|c|c|c|}
\cline { 1 - 5 }$A D A Y Y E R$ & \multirow{2}{*}{$\mathbf{1}$} & $\mathbf{2}$ & $\mathbf{3}$ & $\mathbf{4}$ & $\mathbf{5}$ & $\begin{array}{c}\text { TALEP } \\
\text { (NÜFUS) }\end{array}$ \\
\cline { 1 - 5 }$B \ddot{O} L G E$ & & & & & & \\
\cline { 1 - 5 } $\boldsymbol{A}$ & 4 & 8 & 3 & 1 & 7 & 3000 \\
\hline $\boldsymbol{B}$ & 5 & 5 & 3 & 4 & 3 & 4000 \\
\hline $\boldsymbol{C}$ & 4 & 9 & 2 & 4 & 6 & 2000 \\
\hline $\boldsymbol{D}$ & 6 & 3 & 7 & 5 & 7 & 2400 \\
\hline $\boldsymbol{E}$ & 4 & 12 & 4 & 2 & 9 & 2000 \\
\hline $\boldsymbol{F}$ & 10 & 13 & 6 & 9 & 3 & 1500 \\
\hline
\end{tabular}

Adım 2: Müşteri talebi ile seyahat sürelerine bağlı maliyet çarpılarak oluşturulan taşıma maliyeti matrisi Tablo 2'de yer almaktadır. Elde edilen değerlere göre sütun toplamları alınır.

Tablo 2. Taşıma Maliyeti Matrisi

\begin{tabular}{|c|c|c|c|c|c|}
\hline$A D A Y Y E R$ & & & & & \\
\hline BÖLGE & 1 & 2 & 3 & 4 & 5 \\
\hline$A$ & 12000 & 24000 & 9000 & 3000 & 21000 \\
\hline$B$ & 20000 & 20000 & 12000 & 16000 & 12000 \\
\hline$C$ & 8000 & 18000 & 4000 & 8000 & 12000 \\
\hline$D$ & 14400 & 7200 & 16800 & 12000 & 16800 \\
\hline$E$ & 8000 & 24000 & 8000 & 4000 & 18000 \\
\hline$F$ & 15000 & 19500 & 9000 & 13500 & 4500 \\
\hline $\begin{array}{l}\text { KLİNIK } \\
M A L \dot{I} Y E T \dot{I} \\
(\boldsymbol{E})\end{array}$ & 5000 & 3000 & 6000 & 7000 & 2000 \\
\hline $\begin{array}{l}\text { TOPLAM } \\
\text { MALIYET } \\
\text { (E) }\end{array}$ & 82400 & 115700 & 64800 & 63500 & 86300 \\
\hline
\end{tabular}

Adım 3: Minimum toplam maliyeti 63.500 ₹ olan 4. aday yere ilk geçici aşı kliniği yerleştirilir. Tüm bölgeler bu aday yere (4. aday yer) atanır.

Adım 4: Müşterileri diğer aday yerlere atayarak değerlendirilen yer değiştirme tasarrufları Tablo 3 'teki tasarruf matrisinde yer almaktadır.
Tablo 3. Tasarruf Matrisi

\begin{tabular}{|c|c|c|c|c|c|}
\hline$A D A Y Y E R$ & \multirow[b]{2}{*}{1} & \multirow[b]{2}{*}{2} & \multirow[b]{2}{*}{3} & \multirow[b]{2}{*}{4} & \multirow[b]{2}{*}{5} \\
\hline$B \ddot{O L G E}$ & & & & & \\
\hline $\boldsymbol{A}$ & - & - & - & $A^{*}$ & - \\
\hline $\boldsymbol{B}$ & - & - & 4000 & $B$ & $4000^{*}$ \\
\hline$C$ & 0 & - & 4000 & $C$ & - \\
\hline$D$ & - & 4800 & - & $D$ & - \\
\hline$E$ & - & - & - & $E^{*}$ & - \\
\hline$F$ & - & - & 4500 & $F$ & $9000^{*}$ \\
\hline $\begin{array}{l}\text { KLINIIK } \\
M A L I Y E T \dot{I}(\xi)\end{array}$ & 5000 & 3000 & 6000 & - & 2000 \\
\hline $\begin{array}{l}\text { TOPLAM } \\
\text { MALIYET (E) }\end{array}$ & -5000 & 1800 & 6500 & - & 11000 \\
\hline
\end{tabular}

Adım 5: Bir başka geçici aşılama kliniği ise 11.000 € ile maksimum toplam tasarruf sağlayan 5. aday yere atanır. Bölge B ve F, 5. aday yere atanır.

Adım 6: Müşterilerin diğer aday yerlere atama durmu incelenmiş ve tasarruf matrisi Tablo 4 'te revize edilmiştir. 2. aday yerin tasarrufa sahip olduğu görülmüştür. Bu nedenle algoritmada Adım 5'e geri dönülür ve 1.800 ₹ ile maksimum tasarruf sağlayan 2. aday yere başka bir geçici aşılama kliniği atanır. Bölge D, 2. aday yere atanır.

Tablo 4. Birinci Düzenlenmiş Tasarruf Matrisi

\begin{tabular}{|c|c|c|c|c|c|}
\hline$A D A Y Y E R$ & \multirow[b]{2}{*}{1} & \multirow[b]{2}{*}{2} & \multirow[b]{2}{*}{3} & \multirow[b]{2}{*}{4} & \multirow[b]{2}{*}{5} \\
\hline BÖLGE & & & & & \\
\hline$A$ & - & - & - & $A^{*}$ & - \\
\hline$B$ & - & - & 0 & - & $B^{*}$ \\
\hline$C$ & 0 & - & 4000 & $C$ & - \\
\hline$D$ & - & 4800 & - & $D$ & - \\
\hline$E$ & - & - & - & $E^{*}$ & - \\
\hline$F$ & - & - & - & - & $F^{*}$ \\
\hline 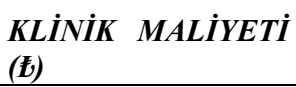 & 5000 & 3000 & 6000 & - & - \\
\hline $\begin{array}{l}\text { TOPLAM } \\
\text { TASARRUF (E) }\end{array}$ & $\begin{array}{c}- \\
5000\end{array}$ & 1800 & $\begin{array}{c}- \\
2000\end{array}$ & - & - \\
\hline
\end{tabular}

Birinci düzenlenmiş tasarruf matrisi Tablo 5 'te bir kez daha revize edilmiştir. Tablo 5'e göre, aday yerlere başka atama yapmanın herhangi bir tasarruf oluşturmadığı görüşür. Böylece yeni bir kliniğe ihtiyaç duyulmadığı anlaşılır ve algoritma sona erer. 
Tablo 5. İkinci Düzenlenmiş Tasarruf Matrisi

\begin{tabular}{|c|c|c|c|c|c|}
\hline$A D A Y Y E R$ & & & & & \\
\hline BÖLGE & 1 & 2 & 3 & 4 & 5 \\
\hline$A$ & - & - & - & $A^{*}$ & - \\
\hline$B$ & - & - & 0 & - & $B^{*}$ \\
\hline$C$ & 0 & - & 4000 & $C$ & - \\
\hline$D$ & - & $D^{*}$ & - & - & - \\
\hline$E$ & - & - & - & $E^{*}$ & - \\
\hline$F$ & - & - & - & - & $F^{*}$ \\
\hline $\begin{array}{l}\text { KLİNİK } \\
M A L I Y E T \dot{I} \\
(\boldsymbol{E})\end{array}$ & 5000 & - & 6000 & - & - \\
\hline $\begin{array}{l}\text { TOPLAM } \\
\text { TASARRUF } \\
\text { (E) }\end{array}$ & -5000 & - & -2000 & - & - \\
\hline
\end{tabular}

Atamaların ve oluşan maliyetlerin son halini içeren final matrisi Tablo 6'da gösterilmiştir.

Tablo 6. Final Matrisi

\begin{tabular}{|c|c|c|c|c|c|c|}
\hline$A D A Y Y E R$ & & & & & & MALIVYET \\
\hline BÖLGE & 1 & 2 & 3 & 4 & 5 & (E) \\
\hline$A$ & - & - & - & $A$ & - & 3000 \\
\hline$B$ & - & - & 0 & - & $B$ & 12000 \\
\hline$C$ & 0 & - & 4000 & $C$ & - & 8000 \\
\hline$D$ & - & $D$ & - & - & - & 7200 \\
\hline$E$ & - & - & - & $E$ & - & 4000 \\
\hline$F$ & - & - & - & - & $F$ & 4500 \\
\hline $\begin{array}{l}\text { KLİNIKK } \\
\text { MALIYYETI } \\
\text { (E) }\end{array}$ & - & 3000 & - & 7000 & 2000 & 12000 \\
\hline $\begin{array}{l}\text { TOPLAM } \\
\text { MALIYET } \\
\text { (E) }\end{array}$ & - & - & - & - & - & 50700 \\
\hline
\end{tabular}

Önerilen sezgisel algoritmanın uygulandığı geçici aşılama kliniği atama problemi sonucunda, üç geçici aş1lama kliniğinin hizmet vermesinin uygun olduğu sonucuna ulaşılmıştır. Bu klinikler, 2., 4. ve 5. aday yerlere atanmıştır. Atamalara göre; 2. aday yere atanan klinik, sadece D bölgesine (bir bölge) hizmet verecektir. 4. aday yere atanan klinik, A ve E olmak üzere iki bölgeye; son olarak 5 . aday yerde bulunan klinik ise $\mathrm{B}, \mathrm{C}$ ve $\mathrm{F}$ olmak üzere üç bölgeye hizmet vermektedir.

Altı bölgeye hizmet verecek üç geçici aşı kliniği atamanın toplam maliyeti 50.700 £ olarak hesaplanmıştır. Tablo 6'da olduğu gibi, 3 . aday yerdeki $\mathrm{B}$ bölgesinin ve 1 . aday yerdeki $\mathrm{C}$ bölgesinin tasarruf maliyetleri sıfira eşittir. Bu durum, söz konusu aday yerlere geçici aşı kliniklerinin atanması durumunda, bu bölgelerin alternatif bir yer ile ilişkili olabileceği anlamına gelir. Fakat algoritma sonucunda 1. ve 3. bölgeye klinik yerleştirmek uygun bulunmamıştır. Bu nedenle, vaka çalışmasında aynı anda iki aday yere hiçbir bölge atanmamıştır. Problemin doğrusal programlama versiyonu GAMS 23.6 yazılımı kullanılarak çözülmüş ve optimum sonuç ile önerilen methodoloji aynı sonuçları elde etmiştir.

Metodolojinin devamında, geçici aşı klinikleri problemine Lagrange gevşetme yöntemi uygulanır. Buradaki amaç, nüfusun hepsinin aşılanması gerekmediği varsayılarak, bir bölgedeki tüm taleplerin atanma zorunluluğu olmadığı durumda toplam maliyeti gözlemlemektir. Vaka analizindeki problemin Lagrange gevşetmesi ile oluşturulan doğrusal programlama modeli aşağıda yer almaktadir:

\section{Girdiler:}

$c_{i j}=$ i'deki müşterinin talebini j'den karşılama (atama) maliyeti (mesafe veya seyahat süresine bağlı maliyet) $(i=1,2, \ldots, n)$ ve $(\mathrm{j}=1,2, \ldots, \mathrm{m})$

$d_{i}=$ i'deki müşterinin talebi

$f_{j}=\mathrm{j}$. aday yere tesis yerleşiminin maliyeti

$k=$ Yerleşim yapılacak tesis sayısı

$u_{i}=$ Lagrange çarpanı

\section{Denklemler:}

$Z(u)_{\min }=\left(4 * 3000-u_{1}\right) x_{11}+\left(8 * 3000-u_{1}\right) x_{12}+$ $\left(3 * 3000-u_{1}\right) x_{13}+\quad\left(1 * 3000-u_{1}\right) x_{14}+(7 * 3000-$ $\left.u_{1}\right) x_{15}+\left(5 * 4000-u_{2}\right) x_{21}+\left(5 * 4000-u_{2}\right) x_{22}+(3 *$ $\left.4000-u_{2}\right) x_{23}+\left(4 * 4000-u_{2}\right) x_{24}+(3 * 4000-$ $\left.u_{2}\right) x_{25}+\left(4 * 2000-u_{3}\right) x_{31}+\left(9 * 2000-u_{3}\right) x_{32}+(2 *$ $\left.2000-u_{3}\right) x_{33}+\left(4 * 2000-u_{3}\right) x_{34}+\left(6 * 20-u_{3}\right) x_{35}+$ $\left(6 * 2400 u_{4}\right) x_{41}+\left(3 * 2400-u_{4}\right) x_{42}+\quad(7 * 2400-$ $\left.u_{4}\right) x_{43}+\left(5 * 24-u_{4}\right) x_{44}+\left(7 * 2400-u_{4}\right) x_{45}+(4 *$ $\left.2000-u_{5}\right) x_{51}+\left(12 * 2000-u_{5}\right) x_{52}+\left(4 * 20-u_{5}\right) x_{53}+$ $\left(2 * 2000-u_{5}\right) x_{54}+\left(9 * 2000-u_{5}\right) x_{55}+\quad(10 * 1500-$ $\left.u_{6}\right) x_{61}+\left(13 * 1500-u_{6}\right) x_{62}+\left(6 * 1500-u_{6}\right) x_{63}+(9 *$ $\left.1500-u_{6}\right) x_{64}+\left(3 * 1500-u_{6}\right) x_{65}+5000 y_{1}+3000 y_{2}+$ $6000 y_{3}+7000 y_{4}+2000 y_{5}+u_{1}+u_{2}+u_{3}+u_{4}+u_{5}$

\section{Şu koşullara göre:}

$$
\begin{aligned}
\mathrm{x}_{11} & \leq 6 y_{1} \\
\mathrm{x}_{12} & \leq 6 y_{2} \\
\mathrm{x}_{13} & \leq 6 y_{3} \\
\mathrm{x}_{14} & \leq 6 y_{4} \\
\mathrm{x}_{15} & \leq 6 y_{5} \\
y_{1}+y_{2} & +y_{3}=3 \\
x_{i j} & \geq 0
\end{aligned}
$$

$$
y_{j}=\left\{\begin{array}{cc}
1, & \text { ĕger tesis j konumuna atanmışsa }, \\
0, & \text { diğer }
\end{array}\right.
$$

Ana problemde bulunan klinik sayısı üç olduğundan, problem toplamda üç klinik için gevşetilmiștir $(\mathrm{k}=3)$. Oluşturulan doğrusal programlama modeli GAMS 23.6 yazılımı kullanılılarak 0.063 sn'de çözülmüştür. Yazılım ile çözülen model, 50 iterasyonda sonuca ulaşmıştır. Kısıt (2)'nin Lagrange gevşetmesi için elde edilen iterasyonlar Şekil 2'de görselleştirilmiştir. 


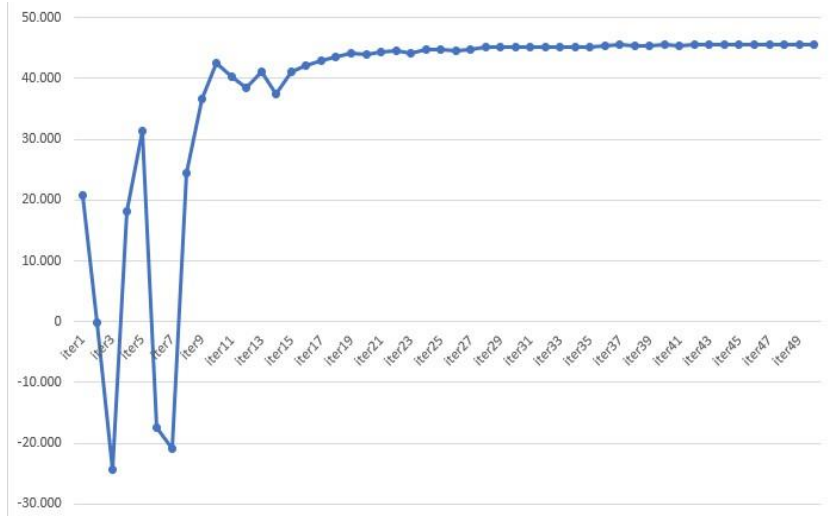

Şekil 2. Kısıt (2)'nin Lagrange Gevşetmesi İçin Elde Edilen Iterasyonlar

Sonuçlara göre toplam maliyet yaklaşık 45.485.540 ₹ olarak hesaplanmıştır. Toplam maliyet, Lagrange gevşetmesi işlemi öncesinde hesaplanan maliyete göre 5.214,46 £ (ilk sonuca göre $\% 10,28$ daha az) azalmıştır. Böylelikle aday yerlere toplam 3 adet geçici aşı kliniği atanmış ve tüm nüfusun aşılanması gerekmediği varsayımı altında toplam maliyet azalmıştır.

\section{Sonuçlar ve Tartışma}

Covid-19 virüsünün neden olduğu salgına karşı geliştirilen aşılar büyük umutlar taşımaktadır. Fakat kitleleri aşılamanın büyük bir yönteimsel sorun teşkil ettiği düşünülmektedir. Bilinen sabit konumlu sağlık merkezlerine ek olarak, aşılamayı hızlandırmak ve Covid-19 süreçlerini diğer hastalıklardan ayrı tutmak için geçici aşılama kliniklerinin kullanımı önerilmiştir. Vaka çalışmasında, İstanbul'un bir ilçesi altı bölgeye bölünmüş ve beş uygun lokasyon aday yer olarak belirlenmiştir. Önce problemin doğrusal programlama modeli kurulmuş ve model Covid-19 aşılaması için çoklu tesis yerleşim problemi için, revize edilmiş tasarruflu sezgisel algoritma ile çözülmüştür. Ayrıca, bölgelerdeki nüfusun tamamının aşılanması gerekmediği varsayılarak, ana modeldeki bir kısıt Lagrange gevşetmesi uygulanarak gevşetilir ve bulunan sonuç ana modelle karşılaştırılır. Geçici aşılama kliniği atama problemi sonucunda beş aday yerden üçüne geçici aşı kliniği yerleştirilmesi 50.700 € ile optimum sonuç vermiştir ve tüm talepler bu kliniklerden karş1lanmıştır. Lagrange gevşetmesi ile her talebin atanması koşulu kaldırılarak, üç geçici aşı kliniğinin toplam maliyeti 45.485.540 €'ye gerilemiştir.

Gelecek çalışmalar için, aday yerlerde hizmet kapasitesi, konum ağırlığ 1 , yönlendirme maliyeti, bölge atama yasağ 1 vb. gibi yeni kısıtlamalar düşünülebilir. Önerilen çoklu tesis atama sezgisel algoritması araç rotalama problemlerine uygulanabilir. Ayrıca, algoritmaların seçilen problemler üzerindeki etkinliğini göstermek için literatürdeki diğer çoklu tesis yerleşim algoritmaları ile karşılaştırılması önerilmektedir.

\section{Kaynakça}

Abdel-Basset, M., Manogaran, G., El-Shahat, D. \& Mirjalili, S., 2018. Integrating the Whale Algorithm with Tabu Search for Quadratic Assignment Problem: A New Approach for
Locating Hospital Departments. Applied Soft Computing, 73, 530-546. https://doi.org/10.1016/j.asoc.2018.08.047

Ackerson, B. K., Sy, L. S., Glenn, S. C., Qian, L., Park, C. H., Riewerts, R. J., \& Jacobsen, S. J. (2021). Pediatric vaccination during the COVID-19 pandemic. Pediatrics, $148(1)$.

https://doi.org/10.1542/peds.2020-047092

Bartsch, S. M., Taitel, M. S., DePasse, J. V., Cox, S. N., SmithRay, R. L., Wedlock, P., Singh, T. G., Carr, S., Siegmund, S.S. \& Lee, B. Y., 2018. Epidemiologic and Economic Impact of Pharmacies as Vaccination Locations during an Influenza Epidemic. Vaccine, 36(46), 7054-7063. https://doi.org/10.1016/j.vaccine.2018.09.040

Chen, W., Misra, S. M., Zhou, F., Sahni, L. C., Boom, J. A. \& Messonnier, M., 2020. Evaluating Partial Series Childhood Vaccination Services in a Mobile Clinic Setting. Clinical Pediatrics, 59(7), 706-715. https://doi.org/10.1177/0009922820908586

Clarke, G. \& Wright, J. W., 1964. Scheduling of Vehicles from a Central Depot to a Number of Delivery Points. Operations Research, 12(4), 568-581. https://doi.org/10.1287/opre.12.4.568

Çakır, E., Taş, M.A. \& Ulukan, Z. 2021. Neutrosophic Fuzzy Weighted Saving Heuristic for COVID-19 Vaccination. In 2021 Systems and Information Engineering Design Symposium (SIEDS), $\quad$ IEEE, $1-4$. https://doi.org/10.1109/SIEDS52267.2021.9483794

Çakır, E, Taş, M.A. \& Ulukan, Z., 2022. Spherical Bipolar Fuzzy Weighted Multi-facility Location Modeling for Mobile COVID-19 Vaccination Clinics. Journal of Intelligent \& Fuzzy Systems, 42(1), $237 \quad-\quad 250$. https://doi.org/10.3233/JIFS-219189

Gianfredi, V., Pennisi, F., Lume, A., Ricciardi, G. E., Minerva, M., Riccò, M., ... \& Signorelli, C. (2021). Challenges and opportunities of mass vaccination centers in COVID-19 times: a rapid review of literature. Vaccines, 9(6), 574. https://doi.org/10.3390/vaccines 9060574

Giles, M. L., Hickman, J., Lingam, V. \& Buttery, J., 2018. Results from a Mobile Outreach Influenza Vaccination Program for Vulnerable and High-risk Populations in a High-income Setting: Lessons Learned. Australian and New Zealand Journal of Public Health, 42(5), 447-450. https://doi.org/10.1111/1753-6405.12810

Hannings, A. N., Duke, L. J., Logan, L. D., Upchurch, B. L., Kearney, J. C., Darley, A., Welch, L. H., Brooks, K. L. \& McElhannon, M. B., 2019. Patient Perceptions of Student Pharmacist-run Mobile Influenza Vaccination Clinics. Journal of the American Pharmacists Association, 59(2), 228-231. https://doi.org/10.1016/j.japh.2018.10.018

Hansen, P. H., Hegedahl, B., Hjortkjaer, S. \& Obel, B., 1994. A Heuristic Solution to the Warehouse Location-routing Problem. European Journal of Operational Research, 76(1), 111-127. https://doi.org/10.1016/0377-2217(94)90010-8

Heymann, D. L. \& Aylward, R. B., 2006. Mass Vaccination: When and Why. Mass Vaccination: Global Aspects-Progress and Obstacles, Springer, Berlin, Heidelberg, 1-16. https://doi.org/10.1007/3-540-36583-4_1 
Kim, N. \& Mountain, T. P., 2017. Role of Non-traditional Locations for Seasonal Flu Vaccination: Empirical Evidence and Evaluation. Vaccine, 35(22), 2943-2948. https://doi.org/10.1016/j.vaccine.2017.04.023

Kuehn, A. \& Hamburger M. J., 1963. A Heuristic Program for Locating Warehouses. Management Science, 9, 643-666. https://doi.org/10.1287/mnsc.9.4.643

Lee, B. Y., Mehrotra, A., Burns, R. M. \& Harris, K. M., 2009. Alternative Vaccination Locations: Who Uses Them and Can They Increase Flu Vaccination Rates?. Vaccine, 27(32), 42524256. https://doi.org/10.1016/j.vaccine.2009.04.055

Leibowitz, A., Livaditis, L., Daftary, G., Pelton-Cairns, L., Regis, C., \& Taveras, E. (2021). Using mobile clinics to deliver care to difficult-to-reach populations: A COVID-19 practice we should keep. Preventive Medicine Reports, 24, 101551. https://doi.org/10.1016/j.pmedr.2021.101551

Mills-Tettey, G. A., Stentz, A. \& Dias, M. B., 2007. The Dynamic Hungarian Algorithm for the Assignment Problem with Changing Costs. Carnegie Mellon University, Pittsburgh, PA, Tech. Rep. CMU-RI-TR-07-27. https://www.ri.cmu.edu/pub_files/pub4/mills_tettey_g_ayor kor_2007_3/mills_tettey_g_ayorkor_2007_3.pdf

New York Times (NY Times). (2022). Tracking Coronavirus Vaccinations Around the World. https://www.nytimes.com/interactive/2021/world/covidvaccinations-tracker.html

Plotkin, S. (2014). History of vaccination. Proceedings of the National Academy of Sciences, 111(34), 12283-12287. https://doi.org/10.1073/pnas.1400472111

Ross, G. T. \& Soland, R. M., 1975. A Branch and Bound Algorithm for the Generalized Assignment Problem. Mathematical Programming, 8(1), 91-103. https://doi.org/10.1007/BF01580430

Srivastava, R., 1993. Alternate Solution Procedures for the Location-routing Problem. Omega, 21(4), 497-506. https://doi.org/10.1016/0305-0483(93)90082-V

Van Barneveld, T. C., Bhulai, S. \& van der Mei, R. D., 2016. The Effect of Ambulance Relocations on the Performance of Ambulance Service Providers. European Journal of Operational Research, 252(1), 257-269. https://doi.org/10.1016/j.ejor.2015.12.022

World Health Organization (WHO). (2021). WHO Coronavirus (COVID-19) Dashboard. https://covid19.who.int/

Wimmert, R. J., 1958. A Mathematical Method of Equipment Location. Journal of Industrial Engineering, 9, 498-505.

Yang, S., Hamedi, M. \& Haghani, A., 2004. Integrated Approach for Emergency Medical Service Location and Assignment Problem. Transportation research record, 1882(1), 184-192. https://doi.org/10.3141/1882-22 